\title{
Crowdsourced cartography: mapping experience and knowledge
}

\author{
Martin Dodge \\ Department of Geography, University of Manchester, Oxford Road, Manchester M13 9PL, \\ England; e-mail: m.dodge@manchester.ac.uk \\ Rob Kitchin \\ NIRSA, National University of Ireland, Maynooth, Co. Kildare, Ireland; \\ e-mail: rob.kitchin@nuim.ie \\ Received 7 September 2011; in revised form 18 May 2012
}

\begin{abstract}
This paper considers the emerging phenomenon of crowdsourced cartography in relation to ideas about the organisation of contemporary knowledge production in capitalist societies. Taking a philosophical perspective that views mapping as a processual, creative, productive act, constructed through citational, embodied, and contextual experiences, we examine how we might profitably analyse collaborative crowdsourced projects like OpenStreetMap to better understand geographic knowledge production in a shifting political economy and sociotechnical landscape. We begin by characterising crowdsourcing practices in the wider context of Web 2.0, which some commentators assert is rapidly becoming a new, dominant mode of knowledge production. We then contextualise Web 2.0 knowledge production, drawing upon the ideas of sociologist George Ritzer, and his notion of 'prosumption', geographer Michael Goodchild's idea of volunteerist 'citizen scientists', and economic commentator Nicholas Carr's critique of the 'ignorance of crowds'. We then go on to discuss the changing nature of cartography in the Web 2.0 era with respect to authorship, ontology, representation, and temporality.
\end{abstract}

Keywords: cartography, crowdsourcing, 'prosumers', Web 2.0, authorship, ontology, representation, temporality

\section{Contemporary knowledge production: Web 2.0}

A burgeoning set of concepts has been used to characterise the emerging nature of contemporary digital knowledge production in Western economies: peer production, free software, creative commons, feeds, blogs, cloud computing, social networking, mash-ups, torrents, tags, tweets, and wikis. These represent new ways to author information and communicate meanings with respect to a raft of increasingly affordable, pervasive, and capable personal digital technologies, such as smartphones, tablets, and notebooks. Collectively, they constitute Web 2.0 - a new era of the Internet differentiated by participation as opposed to broadcast and consumption. Web 2.0 is a read+write media, in which people add value to sites as they use them (O’Reilly, 2005). Such media include social networking sites such as Facebook, blogs, synchronous microblogs such as Twitter, shared gaming spaces and multiuser virtual worlds, mash-ups, media and code distribution services such as YouTube, Flickr, and SourceForge, peer-to-peer file sharing via protocols like BitTorrent, and social tagging and bookmarking.

A radical feature of some elements of Web 2.0 is the use of crowdsourcing to actively design media structures and populate it with content. Crowdsourcing is the collective generation of media, ideas, and data undertaken voluntarily by many people. The crowd as a metaphor signifies the power that can emerge from a mass of individuals converging to tackle a set of tasks. In the virtual realm, a crowd can be drawn together across a widely distributed set of actors for little cost in order to tackle very large challenges (for example, mapping 
whole countries). For individuals or small groups of volunteers this kind of challenge is simply too daunting but, given many thousands of participants, the task can be subdivided and solved. Crowdsourcing then is premised on mass participation, with distributed voluntary effort, and a degree of coordination; it harnesses the 'wealth of networks' (Benkler, 2006, page 2) to utilize "nonmarket and non-proprietary production, both by individuals alone and by cooperative efforts in a wide range of loosely or tightly woven collaborations." Yet a key issue is how to beckon the crowd into being and how to marshal it to form a coherent group working to a common goal. Indeed, the coordination aspect is often the most contentious as motivated individuals can be difficult to corral into meeting shared objectives.

Such crowdsourcing projects challenge traditional notions of knowledge generation by radically transforming the acts of writing, creating, and mapping. In wiki systems, in particular, the authoring of information becomes a collaborative, peer-produced act so that all participants can contribute to the production of a unified text, with rights and facilities to edit, refine, and extend the contributions of others. In opensource software projects many programmers contribute freely their time and labour to produce source code for the benefit of others. In geocrowd mapping projects such as OpenStreetMap (OSM), people voluntarily collect, clean, and upload GPS tracks and add attribute data in order to produce surveyed geospatial information. Novel works can also be constructed in the form of mash-ups that use application programming interfaces (APIs) to combine multiple sources of data in ways not prescribed or necessarily anticipated by the providers. By far the most popular type of mash-up is map based, wherein data from one source, such as photographs in Flickr are fed into another, such as Google Earth, to create a hybrid cartographic service. In all four kinds of knowledge production - wiki, 'free' software, geocrowd mapping, and mash-ups — data and information are published under a range of new licensing regimes, with many authors consciously working under an open rubric, at odds with conventional copyright strictures, using, for example, creative commons, ODbL, or GNU licensing that allow others to fully exploit digital content easily and freely for the social good rather than monetary profit.

The apparent willingness of many people to participate for 'free' in crowdsourcing projects is undoubtedly based on the fact that they provide genuinely effective platforms to connect socially, communicate meaningfully, and contribute collectively. There are, of course, ongoing debates around the worth of these connections and communications, with critics arguing that they are superficial, lacking depth and obligatory commitment (Carr, 2007). There are also concerns over the unpredictability of crowds, their narrow demographic profile [the worry being that they are dominated by unrepresentative digital elites (see Crutcher and Zook, 2009)], the quality and consistency of content and metadata created across diversely skilled/motivated individuals, how to provide documented degrees of reliability and generate a sense of trustworthiness, and the extent to which the model is sustainable (will volunteers continue to give 'free' labour next week, next month, and next year; what happens when the crowd disperses?)

Perhaps more troubling, many Web 2.0 services are owned by entrepreneurs and newly founded corporate enterprises that seek to produce new models of capital accumulation by unlocking unwaged virtual labour and information resources and creating new markets. Indeed, there now exists a dynamic ecosystem of companies offering many different kinds of participatory online services and mobile platforms to support 'free' knowledge production in many forms. These businesses gain benefits at three levels. First, they gain directly authored content (posting, uploads, and sharing) and subsidiary authored information such as comments, tags, ratings, recommendations, forwarding addresses, and cross-linking URLs that together can add up to valuable meta-content. Second, they gain secondary financial benefits through advertising revenue. Third, data relating to site activity and content can be 
combined, classified, and 'mined' for social patterns and commercially valuable trends and fashions, which are packaged and traded to third parties. There are clearly two models of crowdsourcing operating with Web 2.0 mapping. The first is commercially owned, such as Google Maps, where the original base information is professionally sourced and additional information and mass checking is derived from users. Access is currently free, with income sourced from advertising, cross-subsidisation, and payment by companies making mass usage of the API, but the ontology is fixed. The second is an opensource model wherein the entire mapping platform and underlying cartographic database is open, editable, and not owned by a company operating for profit.

The development of Web 2.0 and crowdsourcing raises a number of questions with respect to geographic knowledge production - its quality, reliability, sustainability, and ownershipand its underlying political economy, as well as opening up fundamental questions with respect to authorship, ontology, representation, and temporality. In this paper we examine these questions, focusing in particular on open crowdsourced mapping.

\section{Understanding cartographic crowdsourcing}

In this section we seek to make sense of the phenomenon of crowdsourcing for the production of geospatial data used for mapping in the context of Web 2.0 developments by drawing upon Ritzer's (2008) notion of 'prosumer societies', Goodchild's (2007) conception of volunteerist 'citizen scientists', and Carr's (2007) critique of the 'ignorance of crowds'. Taken together, we posit that these three theoretical positions make clear the attraction, power, and problems of crowdsourcing with respect to the changing nature of the mapping experience and knowledge.

\section{Prosumption}

"the producers of much that exists on Web 2.0 are simultaneously the consumers of what is produced and there is a fluid relationship between production/consumption and producers/consumers. In terms of the latter, this is the emergence of the 'prosumer'."

Ritzer (2008, page 8)

One way to begin to think about the practices of mapping and the changing culture of geospatial data production through crowdsourcing is to conceptualise the era of Web 2.0 as a distinct, new mode of capitalism. This is the thesis of US sociologist George Ritzer in his theory of the 'prosumer society' [see Ritzer (2008) and Ritzer and Jurgenson (2010); see also Benkler's (2006) thesis on the 'wealth of networks']. Ritzer seeks to explain contemporary society by charting the evolving forms of capitalist economic relations. The dominant forms of social organisation are, he contends, the result of ongoing economic struggles between the forces of the market that seek profit and democratic ideals founded on notions of equity. The struggle is played out most overtly around labour power and the relations through which exchange value occurs. Benkler (2006) and Ritzer (2008) make a convincing case that with the rise of Web 2.0 a new mode of labour and exchange has started to emerge, what Ritzer (2008) terms 'prosumption'. Prosumption is a form of consumption in which people fulfil a vital role or add crucial value in the creation of a product or delivery of a service. In the main, prosumers do this additional work for little or no recompense, either getting enjoyment from the task, or a sense of empowerment, or they save money/time as the cost of the service is reduced and often becomes more flexible in nature (such as online banking or checking-in to a flight from home). In return, the service provider or retailer receives unwaged labour, alongside expertise, opinions, and knowledge, and gains efficiencies and potentially valuable information by getting 'closer' to the customers/clients (Ritzer, 2008).

Prosumption capitalism is distinct in how it organises and rewards labour power and restructures forms of exchanges, and is thus different from production-oriented (industrial) 
capitalism and the consumer capitalism that has been the dominant mode in the West for the past half century or so. The emergence of this new prosumer mode of capitalism, however, is not totalising and universal: it has not meant that production-oriented and consumptionoriented modes of capitalism will be replaced and disappear. Here, we consider prosumption and cartography with respect to: (1) the self-service economy; (2) the rise of amateur production; and (3) the prevalence of unfinished products.

It can be argued empirically that consumption practices have shifted quite significantly in recent decades as the self-service economy has broadened across many sectors. More significantly, it has also deepened so that customers/clients must now routinely perform tasks for businesses/institutions that were previously the preserve of paid employees. This shift to self-service has reached a tipping point in the last few years with much greater automation offered through software (see Kitchin and Dodge, 2011). People are increasingly becoming prosumers with respect to purchasing, payment, ticketing, billing, and the tracking of goods. This is also the case with respect to mapping, as online cartographic services enable people to become cartographic prosumers. Rather than rely on prepared cartographic products (like road atlases or paper street maps), prosumers create customised maps on demand, able to set the frame, scale, content, legend, orientation, and colour scheme, depending on the platform. They can also access and layer multimodal geospatial information, able to switch between and overlay map, satellite image, oblique views, street views, and terrain displays, and actively query features, and in some case perform quite sophisticated comparative analysis (eg, searching for new homes). A whole host of institutions and companies now exploit cartographic prosumption for efficient service delivery, compelling customers to answer their own spatial queries or to feedback and report incidents, such as road defects and vandalism to local government (eg, http://www.fixyourstreet.ie).

Many successful commercial firms seek to expand prosumption to be able to profit from distributing unfinished products that require the enrolment of the purchaser to complete them so that they function as intended. This has long been the model of 'flat pack' businesses, such as Ikea's self-assembly furniture. However, it has grown significantly in recent years, with many manufacturers no longer making standard products but, instead, shipping commodities that are bespoke, designed by customers via website options, and assembled to order. Much software that is sold is the apeosis of an unfinished product, with many large applications offering multiple configurations, plug-ins, extensions, and update patches, and are reliant on users to set up their own data structures and source key datasets. The mutability of computer code is in some senses one of the foundation stones of Web 2.0. Software-particularly that which is authored under opensource conditions - is an open-ended authorial tool. In the realm of cartographic production, one might be an effective user of GIS software, but one gains new capacities by being able to upload and share GPS tracks or surveyed data to a web mapping platform such as OpenStreetMap, or to create a mapping mash-up, or being able to program and share code for an online mapping platform that enables new analytical and visualisation functions. It is a shift from being a map reader to being a map maker.

Beside extending self-service interaction, another distinctive feature of prosumptive capitalism is the growth in 'amateur' labour power in various spheres, including media production and knowledge creation. The rise of the amateur is noteworthy both in terms of raw volume (more people volunteering in crowdsourcing) and also in terms of how this labour affects professional/paid workers by supplementing and replacing their contributions. This so-called 'rise of the amateur' is significant for cartography as it represents a fundamental change in the creation of maps. Rather than permitting people to interactively query and customise existing maps, it enables them to prosume a new map into existence. This is powerfully illustrated in the personalisation of maps, with the database software and 
a locationally aware user able to beckon into being maps of the moment. This egocentric cartographic production, most compelling on smartphones, allows amateurs to create their own 'me-maps' which are centred on their geographic location, updating in real time with their movement, and enabling the tagging of points, annotation, and editing of the cartographic information. Importantly, the code behind 'me-map' also remembers its own mapping as a new mode of spatialised surveillance (Dodge et al, 2009).

\section{Citizen scientists}

Goodchild argues that one of the key features of neogeography-that is, new forms of geographical knowledge creation premised on Web 2.0 (see also Graham, 2010)—is what he terms 'volunteered geographic information' (VGI) (Goodchild, 2007), effectively geocrowdsourcing. For Goodchild, the spatial aspects of Web 2.0 — such as the range of new map mash-ups, free labour in authoring wiki maps, tagging of place-based information on virtual globes - is significant for future professional cartographic practice and map studies.

Goodchild (2007) observes that contemporary crowdsourcing can be seen as following longer established trends in 'citizen science' which are "communities or networks of citizens who act as observers in some domain of science” (page 218). Here, people provide empirical observations and detailed measurements of phenomena for free, which are, crucially, of real value as data points for 'proper' science. Citizen scientists are particularly useful in observational terms because they can be geographically distributed and embedded in place through time (using professional research assistants to gather such field measurements is difficult to coordinate and costly). Examples include amateur meteorological measurement made from back garden weather stations and hobbyist astronomers who meticulously observe the night sky. Citizen science became well established through the 20th century as a support to mainstream science, but remains a minority activity dependent on a fair degree of skill and knowledge or specialised equipment (such as a good-quality telescope) and, above all, a considerable amount of motivation and ongoing commitment.

Taking a somewhat technocentric position, Goodchild (2007) argues that for VGI to mature and extend further (with more people enrolled and performing more kinds of mapping) the barriers to entry must be lowered. This will be achieved, in part, by the routinisation of simple digital tools for data collection, embedded in the functionality of mobile devices such as smartphones, and online platforms for information authorship and collaborative knowledge creation becoming easier to use. Goodchild argues that VGI has value and should be nurtured because existing geographic knowledge about the world is incomplete and of variable accuracy. He points out that much of the world remains poorly mapped in terms of basic topographic survey knowledge, in spite of the availability of sophisticated GI tools and high-resolution remotely sensed data. Where essential topographic mapping does exist it may not be wholly current-this is the situation in the USA and elsewhere. In some parts of the world that have been well mapped to date, it is not clear that this will remain the case into the future given the perilous resourcing of state-led survey infrastructures under neoliberalism (see Leszczynski, 2012). The danger is that geospatial infrastructures (based largely on data from state-funded surveying) could conceivably regress with the decline in the status and capacity of state mapping agencies. And it is not a given that the private sector will step-up to fill in the gaps (Rhind, 1997). Profit-driven mapping will not ensure universal, uniform coverage of space as companies will focus on profitable markets such as urban street maps that are relatively easy to capture, package, and sell. Through VGI activities, it is anticipated that many thousands of people can collectively act as a geographically distributed set of sensors, contributing geospatial data that could offer significant aggregate value. 


\section{Critique of crowdsourcing}

A third way of considering the amateur authorship at the heart of crowdsourced mapping is provided by economist and business commentator Nicholas Carr. He sets out a critical argument focused on what he terms the 'ignorance of crowds' (2007). His work seeks to puncture the hype around technologies such as the web, highlighting the potentially detrimental consequences for the real economy from virtualised, volunteer (unwaged) labour. He challenges the assumption that because sociotechnological assemblages like the Internet can provide new ways to organise and conduct existing activities, this will be inherently beneficial for society. He is critical, for example, of the way that web resources and access to online media is active in changing how we think and create, arguing that the 'Internet is making us stupid' (Carr, 2010) in terms of how we engage with information.

Carr also critiques the economic value in crowdsourcing, questioning both the kinds of information that can be effectively produced by Web 2.0 approaches and the quality of mass amateur authorship. Accordingly, he argues that "peer production is best viewed as a means for refining the old rather than inventing the new; that it's an optimisation model more than an invention model” (2007, page 2). In other words, the value of Web 2.0 is not in producing raw content but in terms of being able to assemble an army of editors and checkers who can identify mistakes and improve large preexisting information resources or projects. The potential of the crowd lies in correction and not creation. This kind of labour practice works because it can be easily subdivided and participants can undertake as little or as much as they want without detriment to the progress of the project or the overall quality of the end product.

These observations are interesting in terms of geospatial production, where everyone is an expert on a locality-even if it is just their own street. If one enrols many eyeballs to check and refine existing maps, the labour could be quite potent. Commercial companies like Google and TomTom are beginning to go down the correction route by soliciting people to be prosumers and help spot errors and fix the map as they use the map. However, these companies seem less willing to embrace a completely open model of amateur authorship: they need a degree of centralised command and control as they seek to sell mapping services for a profit.

Exploiting the crowd for purposes beyond checking and correcting, according to Carr (2007), needs tight editorial control to assure quality of authorship. This is the fundamental tension in Web 2.0 between the attractions of open authorship and volunteerist labour and the continuing need for specific goals and guiding institutions. For Carr, crowdsourcing cannot be democratic or egalitarian as it risks quality, authority, and usability. He illustrates this 'ignorance of crowds' through a trenchant critique of the 'poster child' of open amateur authorship, Wikipedia. Despite its undoubted popularity and the impressive amount of material authored in its relatively brief existence, Carr sees this particular knowledge product-and by implication the underlying approach-as deeply flawed. It suffers greatly from variable article quality, which undermines the credibility and authority of the whole; there is no easy means of judging, from a superficial consultation, whether it is factually accurate. While some articles are clearly incomplete and poorly written, others may be flawed by much more insidious problems of biases and selective coverage. The result is an encyclopaedia that grows in haphazard directions, with lengthy articles on insignificant topics that happen to match the prurient interests, obsessions, and populist fads of the small crowd of willing amateur authors. As Carr (2007, page 4) notes, “if Wikipedia weren’t free, it is unlikely its readers would be so forgiving of its failings."

There are potentially deep consequences if Carr's critical interpretation of contemporary political economy of authorship is correct when applied to the domain of geospatial data and cartographic products. The voluntary mapping practices of amateurs will result not only in 
inferior VGI content, but also its free status (both in terms of financial cost and also freedom of use) will negatively impact the profitability of cartographic companies and the viability of state agencies required to cover costs. A key concern is that, for all its youthful energy and spirit of innovation, if OpenStreetMap really heralds the triumph of unwaged amateur labour in determining the exchange value for cartographic production, then professional mapmaking will perish. It would also potentially devalue cartographic skills as people accept poor mapping products as the norm, and further erode the diversity of cartography. In addition, the mapping of certain things and places deemed uninteresting or unimportant by the unrepresentative geocrowd may become overlooked. However, there are countervailing views: it is not at all clear that crowdsourced cartography is inferior to professional cartography (cf Haklay, 2010; Mooney et al, 2011) or that opensource mapping will lack diversity or coverage. Indeed, it may well be the case that opensource and professional cartography might develop in new, symbiotic ways.

\section{The difference crowdsourced cartography makes}

Notwithstanding Carr's critique of the value of amateur efforts, it is, we believe, worth considering the opportunities and benefits that might arise through crowdsourced and prosumptive cartography practised by citizen scientists. The comparison we make is predominately between open crowdsourced mapping, specifically OpenStreetMap ${ }^{(1)}$, probably the best documented VGI project (Haklay, 2010; Mooney et al, 2011; Ramm et al, 2011; Zook et al, 2010), and state-based mapping. More broadly we consider what cartographers and human geographers could gain by exploiting crowdsourcing in creative ways to do new types of research and perform different kinds of learning by doing.

At a practical and pragmatic level, spatial data produced by state agencies and commercial companies can be expensive to access and their use bound by complex licensing deals, expensive recurrent subscriptions models, and restrictive copyright clauses. For example, through the EDINA Digimap service, British academics can purchase institutional access to all current Ordnance Survey digital data for the UK, though it comes with strict licensing conditions concerning use and publication. ${ }^{(2)}$ Such conditions limit academic freedom and constrict research. The ready availability of valuable but costly resources is likely to come under further pressure with widespread cuts in university and research budgets.

Beyond pragmatics of access and the financial sustainability, there is no doubt important research value in studying real world mapping practices as exemplified by crowdsourced projects such as OpenStreetMap (OSM). These projects reveal how processes of collaborative knowledge production occur in practice. As such, they enable a shift in the empirical focus of cartographic research from the rules and science of map-making and what maps represent and mean, to how maps are constructed in practice and do work in the world to solve different tasks. Such an epistemological shift also has the potential to open up larger intellectual questions about the nature of geographical knowledge in contemporary political economy with respect to authorship, the ontology of place, the partiality and accuracy of representation, and temporality of production. These four questions are by no means exhaustive, but are useful entry points for considering the difference that crowdsourcing makes. They make sense in relation to the sociotechnical structure of OSM itself, but also reflect intellectual discussion regarding the novel aspects new media in a so-called 'remix culture' (Manovich, 2001)

${ }^{(1)}$ The primary OpenStreetMap interface is at http://www.openstreetmap.org and further details on the project are given on the wiki, available at http://wiki.openstreetmap.org.

(2) It is also expensive: the University of Manchester pays $£ 6625$ per annum for their Ordnance Survey Digimap subscription. 
and poststructuralist reading of the practices of knowledge creation-what Barthes (1978) famously termed the 'death of the author'.

\section{Authorship}

In conventionally produced geographic knowledge, such as large, centrally organised cartographic surveys by the state, authorship is consciously rendered anonymous. Similarly, commercially produced street atlases and satnav route guides are presented as authorless documents. Naming the authors would suggest subjectivity at play in map creation and denude the pretence of objectivity underpinning the correspondence between graphical signs and the territory represented. Here, there is an attempt to position the cartographic representation as the single objective voice speaking onto space and not a polyvocal, subjective recantation that actually brings the space into being and which acknowledges the full range of multiple authors, with different skills and diverse subjectivities, that have contributed to processes of specification, data collection, checking, processing, drawing, labelling, deleting, designing, and so on. Such an acknowledgement exposes the map to suggestions of fallibility.

Typically, opensource projects and ones that seek to enrol prosumer labour are more candid about their authorship practices. In part, they do this to attract the crowd and retain their labour by rewarding them through the positive acknowledgement and peer recognition of their contributions. In a wiki mapping project like OSM the authorship model by necessity fractures the anonymity of cartography products upheld by commercial organisations and state agencies. As of May 2012 some 441651 people had registered with OSM and 17610 had contributed by editing — quite a sizeable crowd; although the more active set of prosumers labouring on the map during that month by uploading new GPS data was much smaller at 3499 (under 20\%) (OSM, 2012).

As with other VGI projects, in OSM all the geospatial data are created by registered users who become permanently associated in the database with the material they author and contribute. Most significantly, and unlike conventional cartographic production, this detail is publicly available, and can be queried and analysed. Figure 1 presents an illustrative example, mapping the authorship of OSM for Bologna, Italy, revealing the range of authors involved in producing this relatively small area. In total, the mapping crowd comprised 124 different registered users who have made an authorial contribution, although the top ten most active prosumers produced just over $74 \%$ of the map data being displayed. The dominant author is Alberto58, whose work constituted $18 \%$ of the data which form the dense core of the old city centre.

Whilst the primary web interface to the OSM database, rendered in the style of topographic cartographic artefacts, appears similar in many respects to other commercial web mapping portals, crucially, it has extra public functions. This includes an Edit button, shown prominently, which is the gateway to the wiki-based element of the project and allows registered users to change anything they choose. As the marketing slogan for OpenStreetMap states: "free, editable map ... it is made by people like you." Such open editing is a radical departure for cartographic products, shifting from top-down consumption to the opportunity for bottom-up prosumption. It also means that aspects of the processual nature of mapping can be studied.

Within OSM users can click on a data object in the map display to query the record from the database and thus all details on the authorship. This ability to directly query any object and interrogate its properties is familiar to GIS users working on their own (private) database, but is powerfully new for a publicly accessible map of the world. The ability to see the complete technical history (through time and space) of contributors' actions is clearly useful for analysing the processes of authorship (evidence of collaboration and conflict, how incremental improvements have emerged, the impacts of vandalism and the costs of their clean-up, etc). 


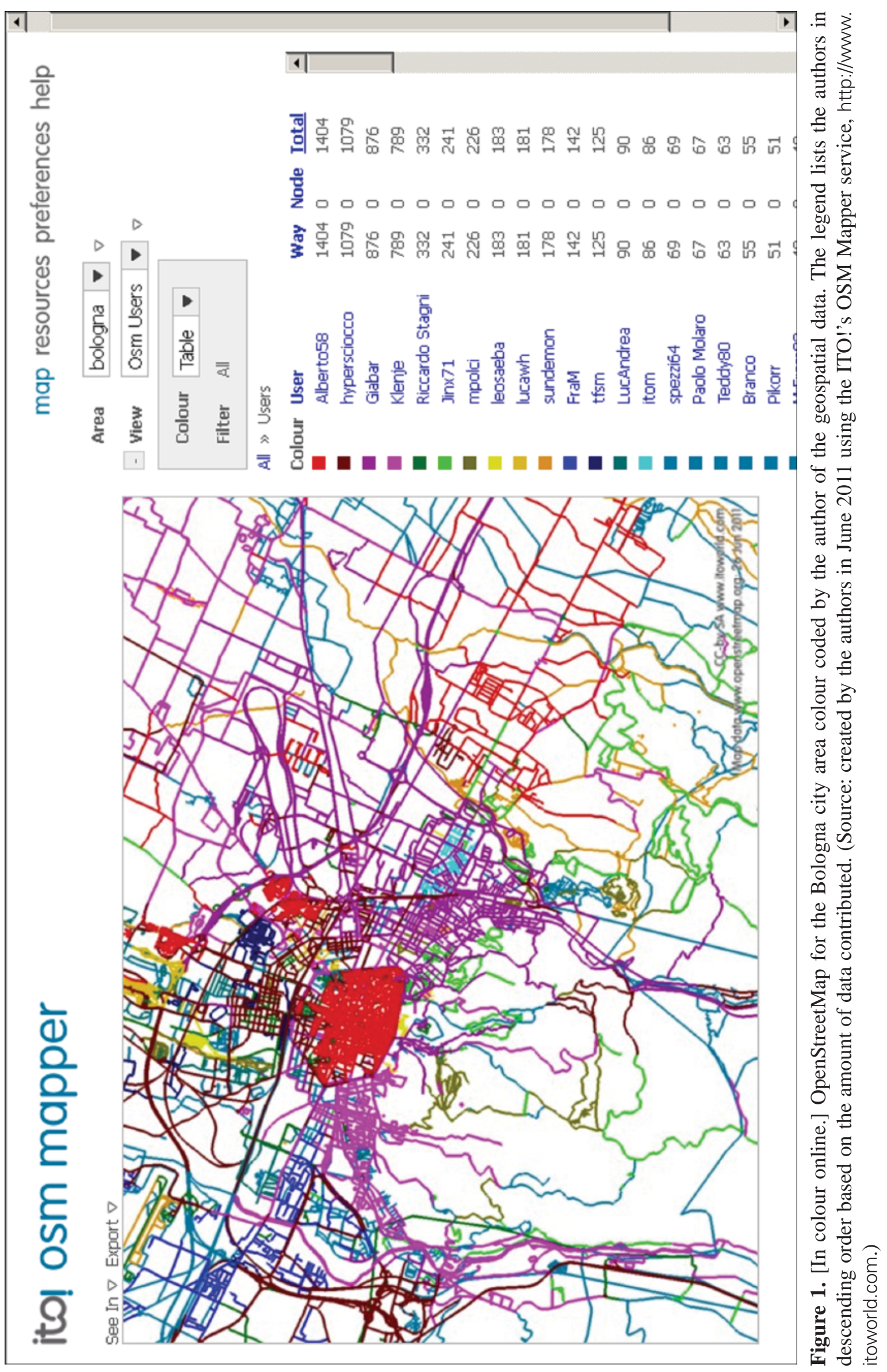


The rise of the amateur is a particular concern for cartography because it threatens to replace, not just supplement, professional surveyors and cartographers. Importantly, there is an element of deskilling going on: it takes much less effort and technical knowledge to record spatial data with a recreational GPS unit than with sophisticated surveying tools. The use of amateur labour also raises issues of coverage, cost, and currency of information production, as well as the integrity and authority of how space is recorded and what is deemed mappable. The danger with crowdsourced data is that they are subjective, emotive, biased, and mired in the personal details; what effective mapmaking really needs is the objectivity and synoptic viewpoint that can only be offered by experienced, professional surveyors and cartographers. What we have here are contrasting value judgments between the value of lots of local viewpoints versus a detached global singular overview. Walking a street, clutching a GPS may offer some visceral reality, but it does not necessarily unlock the truth of a place or generate an effective representation of space, which often only comes from setting immediate features into wider contexts. Arguably, the real political significance of the rise of the amateur comes when the crowd can cut out the hegemonic ('official') map itself to reach a wider range of users directly. Indeed, if geospatial data are increasingly generated by the crowd, to what extent can we trust the process and the product? The trust and authority of traditional topographic maps stems from their authorthe state. Nascent VGI projects, such as OpenStreetMap, clearly lack the capacity to demand authority and it remains to be seen whether people will trust their product.

\section{Ontology}

With a diverse range of mappers drawn as volunteers from the crowd, there clearly needs to be some sense of what of the world should be mapped in projects like OSM. This is a fundamental ontological question at the heart of geographic knowledge creation: what do we need to know about the world, what can feasibly be captured for a given purpose and represented in cartographic form? The new crowdsourced authorship of OSM exposes for public scrutiny such ontological questions and what people choose to capture and how they categorise and describe phenomena.

In conventional cartography, just as multiple authorship is denied, so too are the messy contingencies and selective interests embodied in ontological decisions. Such elisions work to bolster the notion of objective authority. As such, the politics of ontology relating to the selective interests of capitalist accumulation or militaristic agendas that underpin the ontological constitution of state-produced maps lies beyond the map itself. What, for example, is the ontological constitution of Google Maps? It clearly has one and it certainly arose from some debate within the company between GI experts, database specialists, interface designers, and business managers, along with the various contracted data suppliers, concerning what about the world should be mapped and how it should be presented.

The situation is often markedly different with open, crowdsourced, projects where prosumers are active in ontological discussions that mostly take place in online public forums. This is the case with OSM, which has built an open ontology from scratch. Interestingly, many of the people most actively involved in the ontological development of OSM, whilst skilful and self-motivated, are not invested in conventional cartographic expertise and training, and are therefore not inculcated in existing (unwritten) ontological rules. As a result, there are often lively debates about the ontology for OSM (these are also archived and can be analysed over several years $\left.{ }^{(3)}\right)$. With an open-source project potentially nothing is fixed and much is

(3) These can be accessed at http://lists.openstreetmap.org. Other freely available sources on the emergence of OSM's ontology include the open editing of documents, FAQs, and how-to guides on the wiki-especially the accepted-feature list that sets up tagging conventions http://wiki.openstreetmap. org/wiki/Map_Features, regular open sessions on IRC (Internet relay chat) and presentations by leading participants at the 'State of the Map' OSM conferences: http://stateofthemap.org/about/. 
at stake. (OSM inevitably borrows much, often tacitly, from existing cartographic norms, such as topographic conventions and a current focus on roads.) A good deal of reinventing occurs, but also some fresh thinking from outsiders and nonexperts as a new set of 'rules' for mapping the world through crowdsourcing and wiki editing is coming into being.

OpenStreetMap is a valuable 'live laboratory' in which to explore the ontological politics of cartography and the ways in which a mapping ontology appears solid, but is in fact always shifting. It is relatively easy to observe the multiple voices and the majority/minority positions in debates, and how contrary views are expressed and received by others, along with the ways to deal with radically conflicting positions that cannot be reconciled with the existing dominant rule set. It is evident, for example, that OSM's ontology is growing in complexity, from immature beginnings to a fully fledged way of describing the world, but that this is causing tension amongst contributors. Some want more things mapped-a significantly enlarged ontology — but others want a simpler ontology that might more easily be applied universally. [This is evident in changing attribute tags in heavily edited parts of maps (see Mooney and Corcoran, 2012)]. There are also cross-cultural arguments about what counts as important to map and these are a particularly rich area to study. There have been a number of fascinating debates about naming conventions and what features in different parts of the world should be recorded and tagged (such as physical characteristics or legal status). For example, the English tagged 'footpath' does not have the same meaning to most of the rest of the world. ${ }^{(4)}$ Here, one can see how the Eurocentric core ontology, based on a developed physical national infrastructure to consistent standards determined by the state, that dominated at the beginning of the OSM project is being challenged by contributors in other parts of the world where these conventions make less sense.

Ontology is also tied to the politics of display and aesthetic conventions, where contributors tend to favour the national traditions with which they are most familiar [Kent (2009) has shown the significance of national distinctiveness in basic topographic mapping through aesthetic judgments made by the state.] There is a tension between those happy to have an 'untidy' ontology, necessary to encompass local diversity, against those who support a universalist, all-encompassing ontology. Ontological discussions for OSM are also complicated because they overlap with issues of ownership over the data that volunteers are contributing and under what terms this should be licensed for others to reuse. This is particularly contentious in terms of commercial exploitation for profit of OSM data that have been volunteered for free. This is currently an ongoing debate and is unresolved.

\section{Partiality and accuracy of representations}

Crowdsourced projects like OSM are inevitably a work in progress and expose the partiality of all representations of place. Conventional maps, like a state-sponsored topographic sheet, or a street atlas on a satnav screen, assert the propositions of completeness and universality-a totalising god's eye view of the world. Of course, they are not and can never be and this is a key deceit at the heart of the myth of cartographic objectivity (see Harley, 1992). OSM exposes this deceit and allows it to be examined in detail. For example, the open API and free availability of the complete map database allow very different designs and presentation, and also support various comparative interfaces which can present side-by-side or overlay different dates of OSM map data, or juxtapose OSM data, against other mappings. Figure 2 provides an example for Bologna, with OSM data and geographic imagery from another source in linked windows - revealing the partial state of the OSM map or vice versa.

This ability to compare map data is of practical relevance in terms of creating better cartographic products, but it also explodes the persistent myth of maps as 'mirrors' of

(4) Including legal status and the particularities of bridleways versus byeways (see http://www.ramblers. org.uk/info/britain/footpathlaw) as well as physical form. 


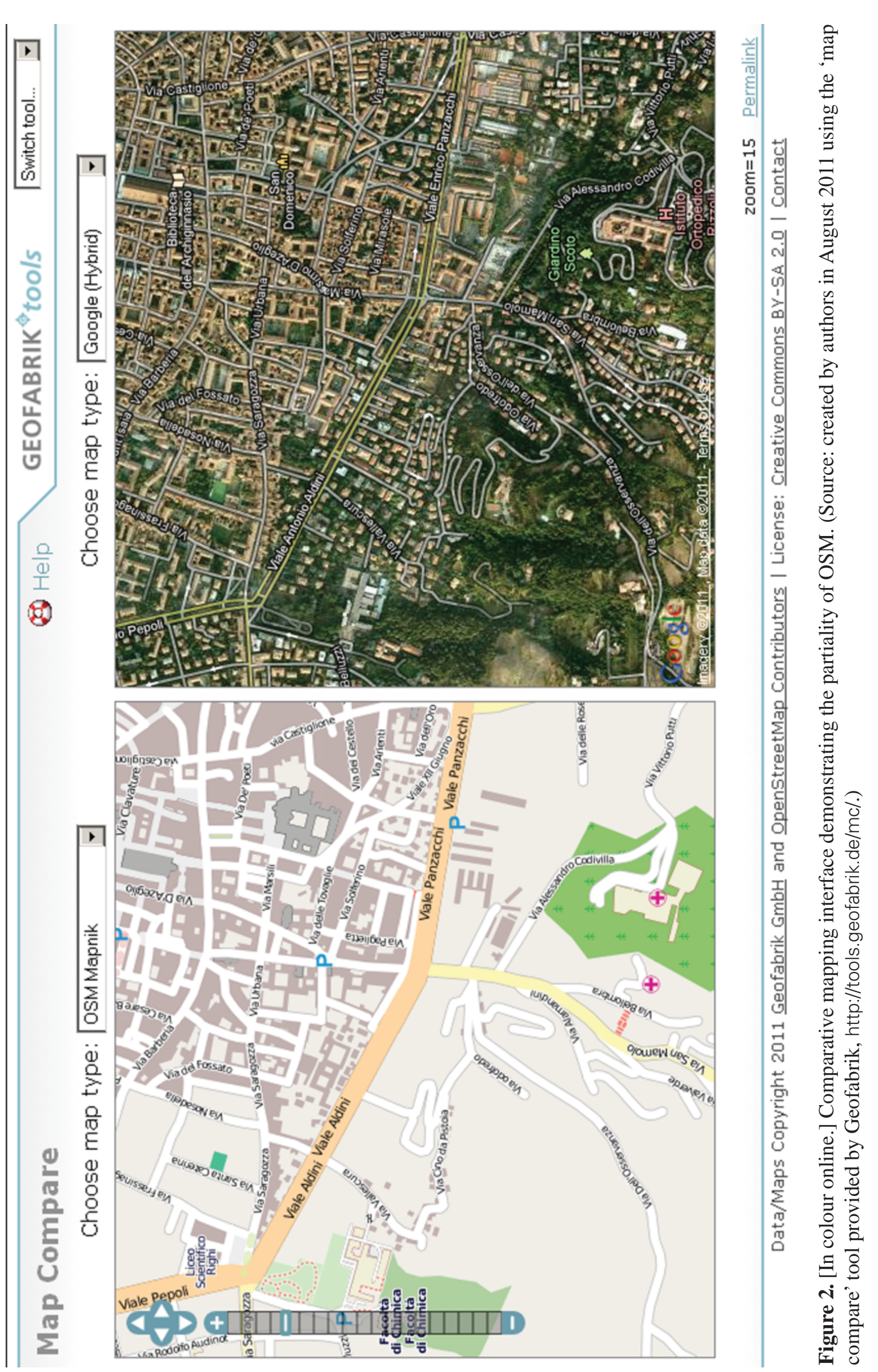


geographic space. The blank spaces on a map are not 'empty' but, rather, voids awaiting ascribed meaning. Pedagogically, OSM's incompleteness reveals how maps emerge through contested, negotiated relational practices, shaped in part by the sociotechnical constraints of the measurement tools employed, such as those used to survey space. As critical cartographers have argued for more than two decades, cartographic information is derived not from the world in some pure and unmediated form, but is constrained by the parameters of capture technologies and filtered through the lens of what is deemed important by cartographers and their paymasters. In the case of VGI projects likes OSM, GPS-enabled technologies play a key role in capturing position data. Whilst GPS appears to be a neutral technology that simply and accurately pinpoints location it is, rather, a very particular way of knowing the world (cf Propen, 2005), and has particular epistemic capabilities that inform and can surveil, and it increasingly empowers commerce and new forms of consumption (Caplan, 2006). It has limits and its own partiality which are often 'black-boxed' from scrutiny. While it promises highly accurate measurements, the degree of precision varies across device, geographic context, and user proficiency. As a result, the use of GPS in projects like OSM introduces degrees of imprecision and variability about location into the mapping database (see figure 3). Working through the 'nuts-n-bolts' of generating meaningful cartographic information in OSM from raw GPS data reveals such partiality and imprecision. Consumers of maps typically do not dwell on how a map comes into being, but as prosumers become enrolled in their making, often from first principles, inevitably they become aware of the many subjective, relational, and contingent decisions being made and the embodied and material practices of mapping with respect to cleaning, abstraction, and generalisation (see figure 3). In conventional mapping the ability to explore and question these practices is denied and the ability to examine raw measurement data is not permitted. However, with OSM the full set of GPS 'breadcrumb trails' that people have uploaded and edited is available for consultation and quantitative analysis (cf Mooney et al, 2011) and interpretation.

With respect to the form of representation, Web 2.0 mapping, despite the possibilities presented by new technologies, largely reproduces existing cartographic conventions. For example, while OSM is a wiki that is open to many ways of mapping, the evidence is that it recreates the same aspects of place that are mapped in state-sponsored maps and its semiotics are highly conventional. And yet there is much scope to push mapping in new directions. Some of the meta-maps deployed here (figures 1 and 4), generated with the 'hidden' process data made uniquely open in OSM, point towards the possibilities. There is also scope for binding OSM with work by artists: for example, Barnes's (2007) work on mapping spaces by recording graffiti or Nold's (2009) work on charting the embodied emotional experience of space.

\section{Temporalities of production}

The practices of mapping occur through time and yet conventional cartographic cultures tend to deny its temporality (eg, a singular year date for print publication). As such, conventionally, cartography representation has lacked temporal sensitivity to the unfolding of the world. Cartography produced by states, for example, portrays a static world in which dynamic, unpredictable, and mobile processes are either ignored or frozen at specific and externally specified points in time. Beyond narrow technical concerns for legible representations, this freezing has important ideological implications because the resulting maps inherently privilege the status quo and entrench power relations that are most easily 'frozen'. The surveyor's gaze has always favoured things that appear fixed in the landscape (or with relatively long durations to human sensibilities). As Bunge (1971, page 4) notes: 


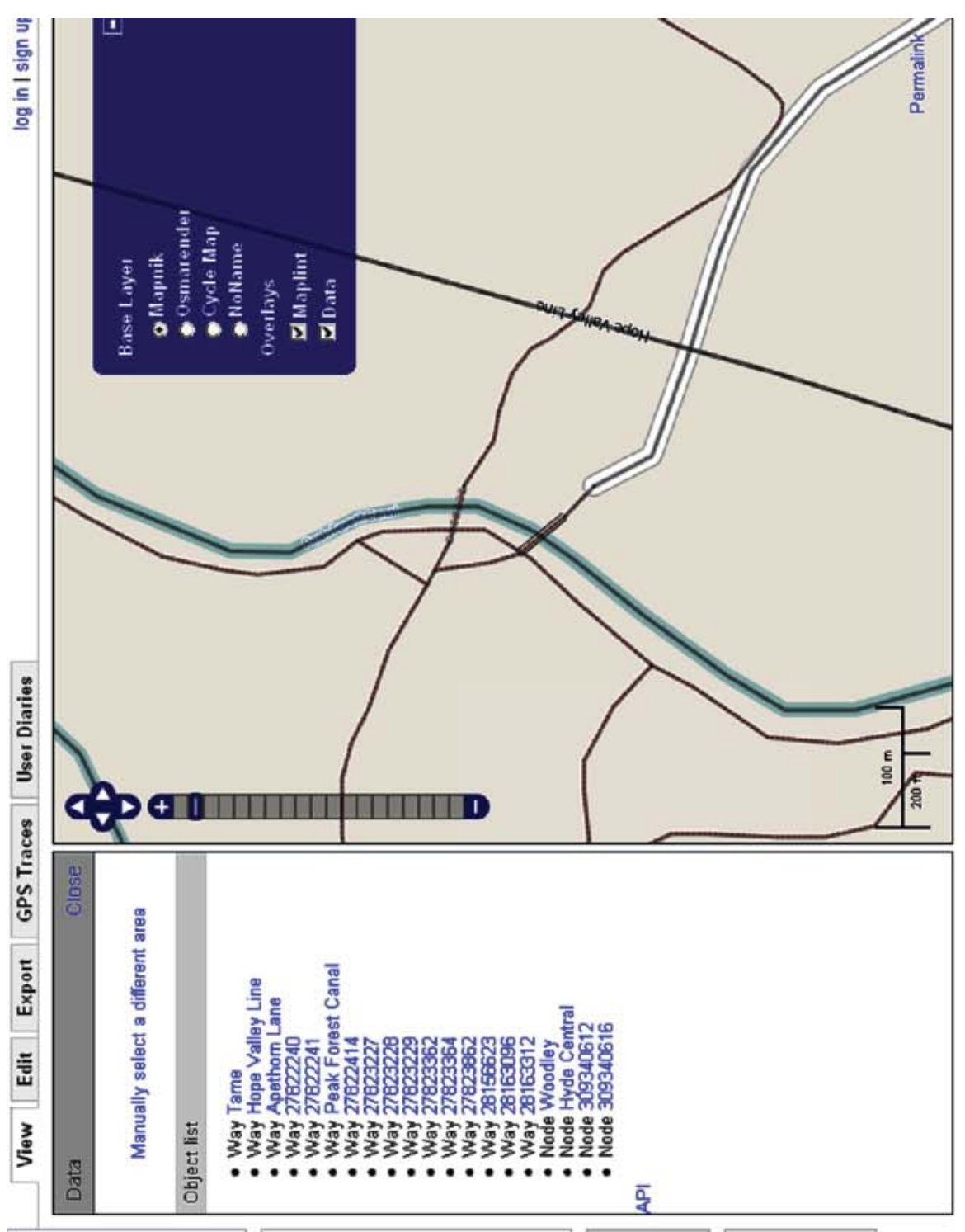

苛

๑

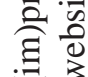

论

a 0

Q

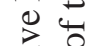

苞

है

उ

总

울

의 음

总责

范

要营

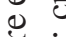

过

i

○。

믐

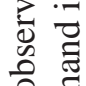

올

ฮี

즐. 옴

\%

을 을

品.

중

灵

氙

o 후

营

跣

F車

寻

킁

킁

응 की

当苍

ले

ํㅗㄹ

总声 


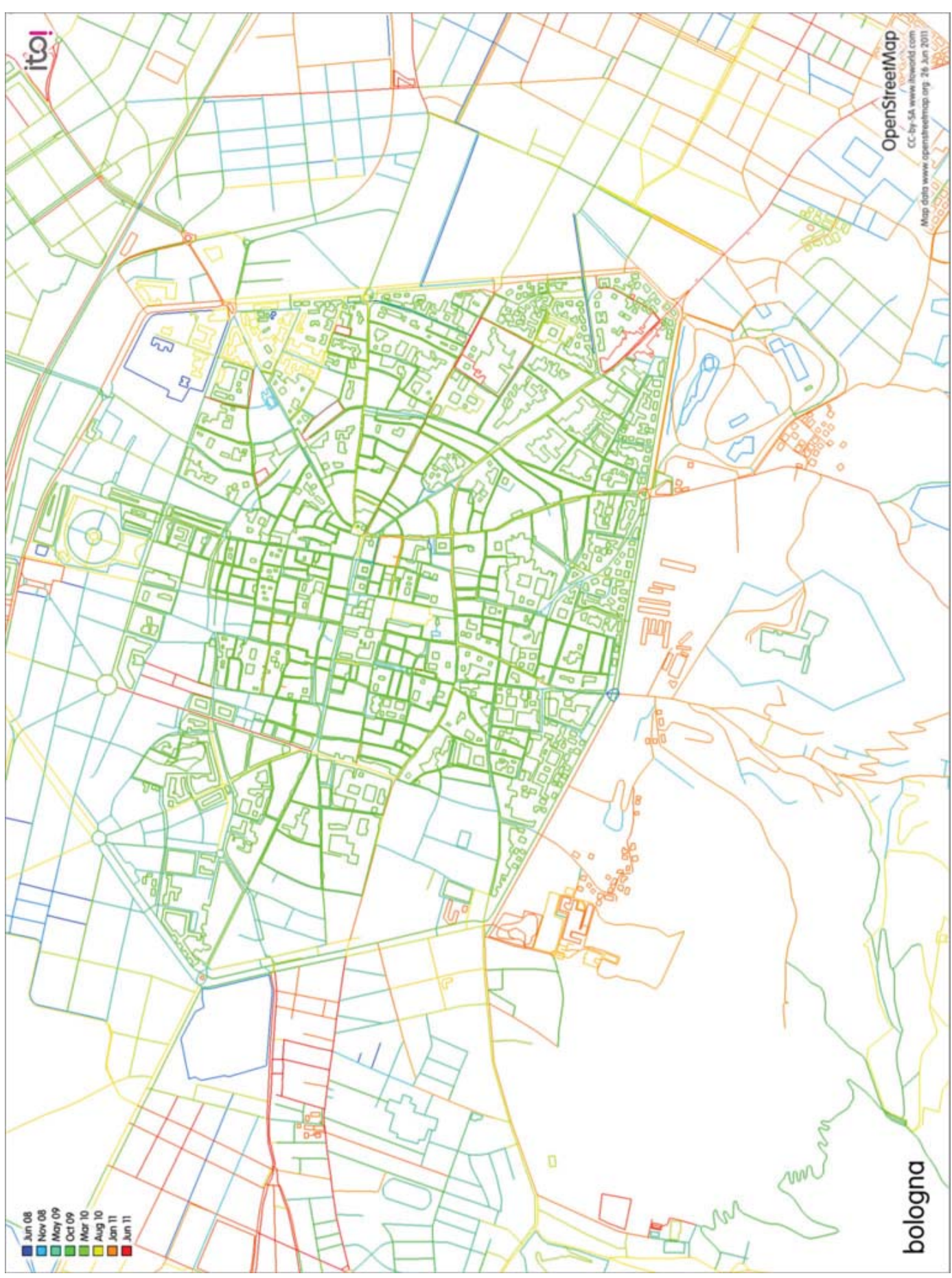

Figure 4. [In colour online.] Temporality of OSM data for Bologna displayed as a thematic meta map. Such maps as memories explode the myth of temporal fixity that underlies conventional cartography. (Source: created by authors in June 2011 from the ITO! OSM Mapper service, http://www.itoworld. com.) 
“ [m]aps attempt to integrate over time, that is, maps assume an average span of time. This means that nothing that moves is mapped, and therefore property is inherently preferred over humans."

Furthermore, most cartography conventionally displays selectively the material results of social and economic processes and not the processes themselves. For example, they map cities in terms of building footprints and not the activities occurring within those buildings, or they map the spatial fixes of capital in detail (roads, factories, houses, fence lines, etc), but not the underlying processes of unequal capital circulation.

OSM is interesting in that the underlying memory of how the map has evolved over time is kept in the database and can be interrogated. When one drills down to interrogate individual spatial objects within OSM it is possible to see its complete genealogy in terms of authorial history and temporal emergence - when it first came into being, history of edits, and how current its present instantiation is claiming to be. And, of course, one can then actually choose to edit the object to bring that part of the map into the present, and thus connect the viewing to the making of the space. This is the simple, but powerful notion of prosumption: the capacity of mapping in the moment of map use, which is certainly not possible with other cartographic products that are only consumable.

As with information authorship, so the patterns of temporal emergence of the OSM map can be rendered into their own analytical maps. As an illustration, figure 4 displays the temporality for the mapping of Bologna. The majority of the city centre was fixed in the middle of 2009 (coloured green) and has yet to be edited and updated further. We could imagine many other potential ways of seeing the memories of mapping practices encoded within the OSM database. Temporalities to explore might include: periodicity of largescale change, durations, sequences, gaps in editing, and bursts of activity. Many thematic analytical displays could be made of the oldest elements, which places are most frequently edited and updated, the spatial sequences and patterns of edits. And such temporal memories could be usefully cross-correlated to the nature of authorship in attempts to offer plausible explanations for varying prosumption patterns across time, space, and time-spaces of the map. This might speak to the un-crowd-like behaviour of crowdsourcing projects, such as sometimes relying on lone individuals and the lack of cooperation between contributors, as well as seeing how activity in OSM arises simply as an outcome of events on the ground (such as a news story about a place, a disaster, a proposal for major new development) and speaks to the issues of motivation and sustainability and the degree to which a community might come to care for a crowdsourced map of its meaningful places. Such temporal mapping would itself become a rich memorial device if it was to be continually changed over decades.

\section{Conclusion}

In this paper we have examined the significance of Web 2.0 and crowdsourcing with specific respect to contemporary mapping experiences that underlay geographic knowledge production. Crowdsourcing is radically transforming the acts of making and using maps, fusing what were traditionally two separate practices, and altering fundamentally the political economy of the cartographic industry. We have argued that this is the case because Web 2.0 platforms and crowdsourcing participation engender a new form of productive exchangeprosumption - and utilise the power of the crowd as citizen scientists. People are no longer compelled to purchase and consume maps. Rather, they can access free to use mapping systems that enable them to prosume a map, able to customise the representational 'look' of the map interface, undertake elements of spatial analysis, and, crucially, add to and edit the actual base cartographic information. They can act as 'citizen scientists', voluntarily contributing valuable spatial information to the mapping cloud, and then use this information to solve geographic tasks that matter. In so doing, we are beginning to see how prosumers 
can bypass the traditional processes by which maps are produced, published, and consumed, and reconfigure the economic model of the cartographic data industry, posing threats to state and private producers of data, especially given neoliberal rollback in state agency funding (see also Leszczynski, 2012).

Moreover, the experience of crowdsourced mapping poses challenges to the professional authorship and normative ontology of cartographic representations and their supposed fixity, objectivity, and authority. The production of crowdsourced mapping does not rely on professional training, experience, and knowledge. Their message and ontology are not in the control of a single organisation or cartographer. Rather, they are explicitly polyvocal in authorship and the genealogy of author contributions, collaborations, and conflicts is often publicly recorded and open to scrutiny. The message and ontology is collectively and openly negotiated and, again, this is subject to enquiry and available for analysis by scholars and others. In addition, crowdsourced ventures such as OSM reveal the partiality and politics of map representations and temporalities inherent in the mapping experience. Such representational and temporal contingencies are typically suppressed within traditional cartographic production and distribution. Crowdsourced mappings thus open up more fundamental ontological and epistemological questions about the nature of maps and mapping, a debate that has unfolded over the past twenty years with the development of critical cartography (cf Crampton, 2009; Elwood, 2008).

Despite the opportunities presented by crowdsourcing, some have questioned whether it can create information that is authored consistently, and with sufficient quality to match that produced by smaller numbers of paid professionals working in more conventional modes. Concerns relate to the evenness of coverage, consistency and accuracy of content and metadata, along with ongoing commitment and sustainability in labour exchanges without employment contracts and salary obligations. Quantitative analysis demonstrates that projects like OSM can produce geospatial data from field surveys that match professional standards (Haklay, 2010) and there is little evidence to date of 'the ignorance of crowds' feared by Carr (2007). Despite the rhetoric of mass involvement, it must be acknowledged that OSM is crowdsourced by a few and not the many, with only a small active group who are setting the ontology and doing much of the mapping labour. In other words, there is a relatively small number of dedicated prosumers in comparison with the large number of consuming 'free-riders'. Moreover, it could be legitimately argued that projects like OSM constitute a huge amount of wasted energy in remaking what already exists simply to circumvent cost, copyright, and licensing restrictions.

Regardless of the various issues and critiques aimed at crowdsourced mapping, it is clear that cartographic data generation and map making as an industry has been fundamentally altered by opensource software technologies and Web 2.0 platforms. The mapping experience is being transformed. Whilst we have sought to explain the differences that crowdsourced cartography makes, it is clear that more work needs to be undertaken to empirically research and think through and make sense of the profound changes taking place.

Acknowledgements. An earlier version of this paper was presented at the University of Bologna in June 2011 and we are grateful to Francesco Mazzucchelli and Patrizia Violi for the invitation to participate in their workshop. We also acknowledge the productive discussions with Chris Perkins, and the forbearance of the guest editors Matthew Wilson and Mark Graham.

\section{References}

Barnes A, 2007, "Geo/graphic mapping” Cultural Geographies 14 139-147

Barthes R, 1978, “The death of the author”, in Image, Music, Text (HarperCollins, London) pp 142-148 Benkler Y, 2006 The Wealth of Networks: How Social Production Transforms Markets and Freedom

(Yale University Press, New Haven, CT) 
Bunge W, 1971 Fitzgerald: Geography of a Revolution (Schenkman, Cambridge, MA)

Caplan K, 2006, "Precision targets: GPS and the militarization of consumer identity", American Quarterly 58 693-713

Carr N G, 2007, “The ignorance of crowds” Strategy + Business Magazine 47 1-5

Carr N, 2010 The Shallows: What the Internet is Doing to our Brains (Atlantic Books, New York)

Crampton J W, 2009, “Cartography: maps 2.0” Progress in Human Geography 33 91-100

Crutcher M, Zook M, 2009, "Placemarks and waterlines: racialized cyberscapes in post-Katrina Google Earth” Geoforum 40 523-534

Dodge M, Perkins C, Kitchin R, 2009, "Mapping modes, methods and moments: a manifesto for map studies”, in Rethinking Maps Eds M Dodge, R Kitchin, C Perkins (Routledge, London) pp 220-243

Elwood S, 2008, "Volunteered geographic information: future research directions motivated by critical, participatory, and feminist GIS” GeoJournal 72(3/4) 173-183

Goodchild M F, 2007, "Citizens as sensors: the world of volunteered geography” GeoJournal $69211-221$

Graham M, 2010, "Neogeography and the palimpsests of place” Tijdschrift voor Economische en Sociale Geografie $101422-436$

Haklay M, 2010, "How good is volunteered geographical information? A comparative study of OpenStreetMap and Ordnance Survey datasets" Environment and Planning B: Planning and Design 37 682-703

Harley J B, 1992, "Deconstructing the map”, in Writing Worlds: Discourse, Text and Metaphor in the Representation of Landscape Eds T J Barnes, J S Duncan (Routledge, London) pp 231-247

Kent A, 2009, "Stylistic diversity in European state 1:50 000 topographic maps" The Cartographic Journal 46 179-213

Kitchin R, Dodge M, 2011 Code/Space: Software and Everyday Life (MIT Press, Cambridge, MA) Leszczynski A, 2012, "Situating the geoweb in political economy" Progress in Human Geography 36 72-89

Manovich L, 2001 The Language of New Media (MIT Press, Cambridge, MA)

Mooney P, Corcoran P, 2012, “The annotation process in OpenStreetMap” Transactions in GIS DOI: 10.1111/j.1467-9671.2012.01306.x

Mooney P, Sun H, Corcoran P, Yan L, 2011, “Citizen generated spatial data and information: risks and opportunities" Proceedings of the 2nd International Conference on Network Engineering and Computer Science (ICNECS 2011), Xi'an, Shaanxi, China, http://www.cs.nuim.ie/ pmooney/websitePapers/Mooney-et-all-Submitted-May2011.pdf

Nold C, 2009 Emotional Cartography: Technologies of the Self http://emotionalcartography.net

O’Reilly T, 2005, "What is Web 2.0: design patterns and business models for the next generation of software”, mimeo, http://www.oreillynet.com/pub/a/oreilly/tim/news/2005/09/30/what-is-web-20. html

OSM, 2012 OpenStreetMap Statistics http://www.openstreetmap.org/stats/data_stats.html

Propen A, 2005, “Critical GPS: toward a new politics of location” ACME: An International E-Journal of Critical Geographies 4(1) 131-144

Ramm F, Topf J, Chilton S, 2011 OpenStreetMap: Using and Enhancing the Free Map of the World (UIT Cambridge, Cambridge)

Rhind D, 1997 Framework for the World (GeoInformation International, Cambridge)

Ritzer G, 2008, “Production, consumption ... prosumption?”, mimeo http://www.georgeritzer.com

Ritzer G, Jurgenson N, 2010, "Production, consumption, prosumption: the nature of capitalism in the age of the digital 'prosumer'” Journal of Consumer Culture 10(1) 13-36

Zook M, Graham M, Shelton T, Gorman S, 2010, "Volunteered geographic information and crowdsourcing disaster relief: a case study of the Haitian earthquake” World Medical and Health Policy 2(2) 7-33 